\title{
How Does Online Fundraising Platform Promote Public Donation in China?-An Empirical Analysis From Tencent Fundraising Platform
}

\author{
XU Wen-wen, ZHANG Lei \\ China University of Mining \& Technology, Beijing, China
}

\begin{abstract}
At present, the huge problem that China's Non-profit Organizations are facing is the low efficiency of public fundraising. However, the newly appeared Online Fundraising Platform indicates some possibilities in overcoming the obstacle for public fundraising. Among which Tencent Online Fundraising Platform becomes the typical and the point cut of exploring Online Fundraising Platform Improving Efficiency Mechanism of public donation. Online Fundraising Platform is similar to the online United Way, relying on the advantages of the Internet and the united fundraising to build a ecosystem of public donation which has professional fundraising system, good charity atmosphere, excellent policy environment and crossover cooperation resources. And in which, many factors get improved in pubic donation influence factors system. For one thing, Charity atmosphere and policy environment can be shaped better. For another, the charities can transmit fundraising information in inexpensive and high-efficiency way, and must ensure the transparency of project and donation. Finally, it will be more convenient for donors to get charitable information, make donations and supervise the nonprofit organizations.
\end{abstract}

Keywords: Online Fundraising Platform, public donation influence factors system, public donation, improving efficiency mechanism, Tencent Online Fundraising Platform

\section{The Question Raised: How Does Online Fundraising Platform Promote Public Donation in China? ${ }^{1}$}

According to the latest released data from China Charity Contribution Report 2015 and Giving USA 2016: The Annual Report for Philanthropy for the Year 2015, China's total charitable donations is 11,187.7 million yuan in 2015 (China Charity, 2016), compared with the total donations in USA, 373.225 billion dollars, which is more than 20 times of that of China (China Charity, 2016). Among the total charitable donations of China, enterprise donations accounted for $70.72 \%$, while public donations accounted for only $16.38 \%$ (China Charity, 2016). We are very different from the USA, whose public donations accounted for $72 \%$ of its total donations (National Philanthropic, n.d.). Although the level of economic development will affect the amount of charitable donations, but to some extent, the data above can illustrate that China's public donation resources are not fully developed. The insufficient use of public donation resources not merely shelved a huge amount of charitable

XU Wen-wen, Associate Professor, School of Law and Humanities, China University of Mining \& Technology.

ZHANG Lei, Undergraduate, School of Law and Humanities, China University of Mining \& Technology.

${ }^{1}$ In this article, public donation means individual small donation. 
resources, but caused many serious problems, such as the public institution will lose the autonomy for the over reliance on the major donors, the public lose the opportunity to participate in public welfare, social charity atmosphere gets no training, etc. (XU, 2013). Nevertheless, low account, high cost of single donation of the public donation, management difficulties and other problems (XU, 2013) making many Non-profit Organizations in our country away from public fundraising. Besides, "the unknown use of Lottery money", "astronomical tents", "Guo Meimei incident" and other public welfare scandals have also directly cause some people to resist charitable donations.

In this context, the new things, online fundraising platform, which is created from the collision between the Internet and the public benefit institutions, shows the possibility of breaking the public fundraising bottleneck. Ministry of Civil Affairs announced the first 13 Internet fundraising platform of official certification on August 22, 2016 (Sohu, n.d.), Online fundraising platform officially ended the situation of shortage of legal system. At the end of 2015, four major domestic network fundraising platforms (Micro Public Good, Tencent Online Fundraising Platform, Taobao public welfare) reached more than 3 billion people, and the donations were amounted to 966 million yuan, accounting for $10 \%$ of individual small amount of individual donations (Single amount in the RMB 10,000 yuan) ratio. Among them, what the "Tencent public service" network fundraising platform (hereinafter referred to as "Tencent public welfare") raised were increased by 437.38\% than the previous year (China Charity, 2016).

What is the advantage of the online fundraising platform when facing public fundraising? How can these advantages to promote public donations? These problems are worthy of consideration in academic and public welfare institutions.

At present, the research on online fundraising platform is mainly focused on the two following perspectives: First, transmission and operation mechanism of online fundraising platform (WANG \& ZHANG, 2014; ZHANG \& FU, 2014); Second, developments, advantages, problems and solutions of online fundraising platform (Joellen, 1999; Liazos, 2000; ZHANG \& HOU, 2014; SHI, 2016). The research results above, more or less, are involved in the efficiency of public fundraising on online fundraising platform, however, there is little systematic research on the public donation improving efficiency mechanism of online donation platform both in domestic and foreign academic circles. And "Tencent public interest" of rapid development just gives us an entry point of analyzing deeply how online donation platform benefits the public donation.

\section{Theoretical Framework: Public Donation Influence Factors System}

Public donation is influenced by many factors. Online donation platform improves the public donation greatly, the essence of which is to improve the effect factors of public donations, thus stimulating public donation wills and contribute to donations. Therefore, the start of this study is to build public donation influence factors system.

Research results on the public donation influence factors are very rich, especially in foreign academic field. However, due to the uniqueness of public policy in charitable sector in China, the research results in foreign academic field can't be fully applied to the analysis of public donation in our country. Therefore, this essay, which is based on the systematic research on the existing research results and combine with characteristics of Chinese charitable donations, constructs public donation influencing factors system, as shown in Figure 1, which refers to four aspects: donation environment, donors, Non-profit Organizations and fundraising strategies. 


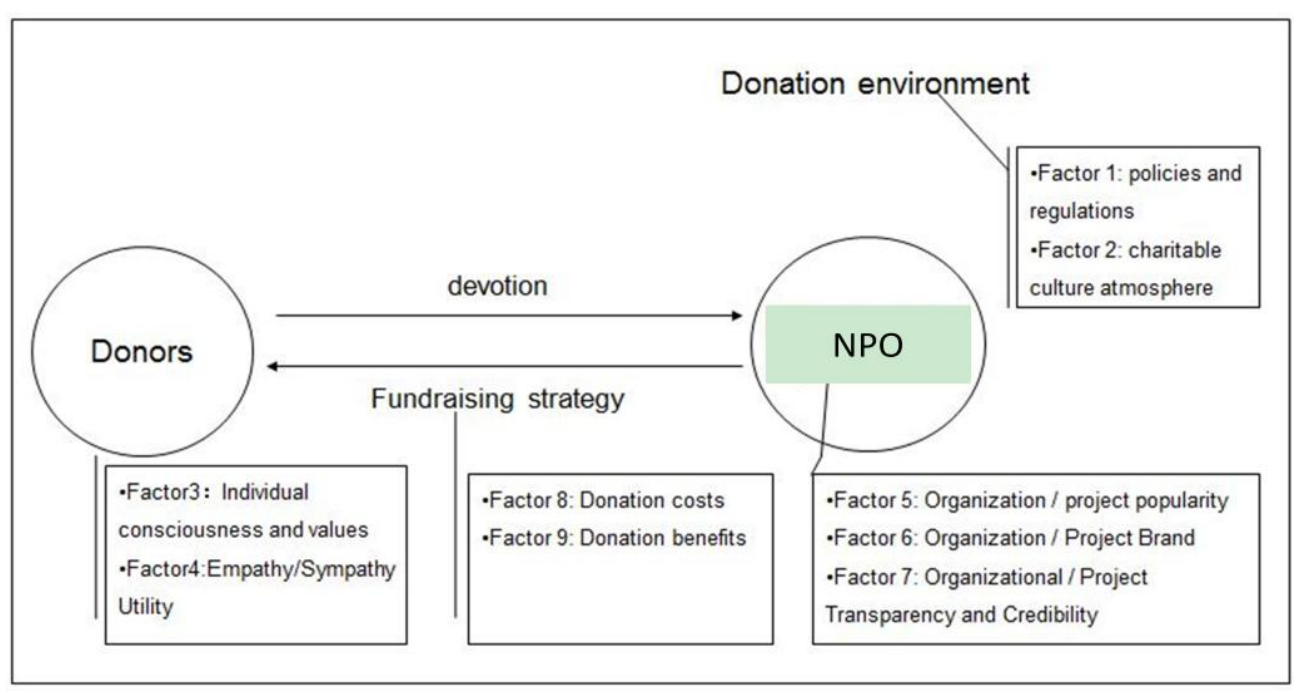

Figure 1. Public donation influence factors system.

\section{Donation Environment}

Simmel argues that when a person joins a group, he will subject to group constraints and influence of others' behavior (Simmel, 1955). Thus donation environment will affect significantly public donation behavior, while policies and regulations and charitable culture atmosphere are two core factors in donation environment.

Factor 1: policies and regulations. In the process of nonprofit organizations becoming normalize, effectively carrying out various activities, there is no doubt that the relevant legal policy environment is the most important influencing factor (WANG \& JIA, 2003). According to the law, charitable organizations, must obtain public fundraising qualifications before carrying out public fundraising ${ }^{2}$. Although the basic requirements of applying for public offering are gradually reduced (charitable organizations which registered legally for two years can apply for the qualification of public offering to Civil Affairs Department ${ }^{3}$ ), but only a small number of public organizations have legal qualification of public offering. In China, the restrictions of public offering of policies and regulations make lots of nonprofit organizations can't raise public funds legally, thereby restrain the development of public donation market.

Factor 2: charitable culture atmosphere. The development of charity in our country experienced three different stages (KANG, 1999), relatively, the charitable culture atmosphere in our country has also changed (JIANG, 2011).

The first stage, There is no charitable culture atmosphere. This stage is the beginning of exploration to the socialist construction in our country, by affection of "benevolent idea" in traditional Confucius culture and the spirit of socialist collectivism, government takes charge of everything in people's life. People was supposed to participate in charity activities by following administrative instructions of relevant departments, so this stage has no charitable culture atmosphere.

The second stage, charitable culture's infancy. With China's economic and political reform deepening gradually, government begin to reduce the control of the society and introduce a series of policies and regulations to achieve opening of the charity sector, in China, the number of charity organizations boom. But the gap between the rich and the poor-making a lot of people mistakenly believe that the essence of charity is

\footnotetext{
2 Note: Quote form article 22 of Charity Law of the People's Republic of China.

${ }^{3}$ Note: Quote form article 22 of Charity Law of the People's Republic of China.
} 
"robbing the rich and poor", charity is only the thing of the rich, so although some of the public charity began to sprout, but overall is weak, and the Public initiative is insufficient.

The third stage, charitable culture atmosphere is becoming strong increasingly. In recent years, the Communist Party of China and state leaders come to realize the importance of charitable culture and begin to put it on the agenda. The public charity awareness is also awaking, especially after the Wenchuan earthquake in 2008, people began to realize that everyone could participate in charity, people's charitable enthusiasm are driven. Charitable atmosphere of the Society is becoming strong.

\section{Donors}

Factors 3: individual consciousness and value. Bekkers and Wiepking (2011) suggests that consciousness and value are the two important mechanisms that affect donation behavior. Many scholars' research show that the consciousness of helping people is stronger, the possibilities of donation behavior are bigger (Lee \& Farrell, 2003), people who have the characters of humanitarianism (Fong, 2007), prosocial values (Van Lange, Bekkers, Schuyt, \& Van Vugt, 2007), altruistic values (Bekkers \& Schuyt, 2008), pay attention to social order fair (Todd \& Lawson, 1999) are more likely to give charitable donations.

Factor 4: empathy/sympathy utility. Some scholars chose to research on personal donation behaviors from the perspective of emotion, and they found that people would devote their love to nonprofit organizations for their own guilty, or empathy resulting from the intimate and deep relationship developed among the people who are similar to those that were rescued by nonprofit organizations (Bruce, 1998), for example, Sargeant et al. found in their research, "I donate to the Small Animal Protection Association because my puppy died of illness, so when the Y charity organization persuade me to donate, I think my donation can help others' pets" (Sargeant, Ford, \& West, 2006).

\section{Non-profit Organizations / Public Welfare Projects}

Factor 5: organization / project popularity. The first step to achieve public donations is to increase public welfare projects' popularity in the public, that is, people may make donations unless they know information about the project. Although public welfare industry in China is in a state of rapid development, but the extent of understanding, how the public understand public welfare establishments, is still remain in the shallow surface. Therefore, it is more important to enhance the effectiveness of project information dissemination, expand the visibility of the project for public fundraising in our country

Factor 6: organization / project brand. Whether profit organizations or nonprofit organizations, the brand is a key resource for building and maintaining the advantage of competition (Aaker, 1997), which can help make organizations different from their competitors, achieve prior social respect and strengthen contact with target customers (Wong \& Merrilees, 2005). Vestlund (2006) argues that making donations to a nonprofit organization is similar to buying a commodity, choosing donation to organization is depends on the feeling of organization's brand (Vestlund, 2006). If the brand image which public organizations shows to outside world are better, its fundraising information is more likely to be trusted and widely disseminated, and the personal willingness to donate will be enhanced, thus can influence public donation decisions (HOU \& DU, 2011; CHEN \& YAO, 2012).

Factor 7: organizational / project transparency and credibility. Credibility is the lifeblood of the survival and development of nonprofit organizations (ZHANG, 2013). A charitable organization must strengthen information disclosure system and ensure the transparency of information if they want to enhance 
their credibility and get recognition and trust. The research of SAXTON and other scholars shows that effective information disclosure mechanism can allow donors to know the whereabouts of donations and the results in time. Voluntary information disclosure can develop organizational credibility and attract more donors (SAXTON, KUO, \& HO, 2012), and the amount of fundraising received by the organization will also be larger (ATAN, ZAITON, \& WAH, 2012).

\section{Fundraising Strategy}

According to social exchange theory, people always make cost-benefit analysis in social exchange, hoping the benefit in direct proportion to the cost. Analyzing charitable donations of this perspective, donors will get more benefits and strengthen donation willingness if they pay smaller cost, the probability of individual donation behavior will also rise. Thus, Non-profit Organizations' fundraising strategy should try their best to minimize the "cost" and maximize the "benefit" of donors.

Factor 8: donation costs. Donation costs are the costs of individual donation behavior, including the cost of collecting donation information, searching for donation channels, implementing donations, supervising the use of donations and tax costs (CAI, 2011). They become easier to have feelings of resistance and the possibilities of donations will be decreased deeply when individual donors feel that the process of participation in donation are more complex, the cost are more (HOU \& DU, 2011; Karlan \& List, 2006).

Factor 9: donation benefits. The discussions of donation benefits in existing literature are mostly from two aspects: the first is invisible income, mainly refers to perception with satisfaction and happiness from donors' individual devotion to public welfare establishments and society (Tankersley, Stowe, \& Huettel, 2007; Smith \& McSweeney, 2007). The second is dominant income, including the material incentives are given by nonprofit organizations (such as self-made postcards and other small gifts) fame and accumulation of social relationships from sharing action of donations in social network.

Above all, this paper will elaborate nine factors in the Public Donation Influence Factors System, and then, this paper will research on how online donation platform is influenced by the factors above, based on individual donation Influence Factors System, taking Tencent Online Fundraising Platform as an example.

\section{Empirical Study: “Tencent Online Fundraising Platform” How to Improve Public Donations? ${ }^{4}$}

Tencent Online Fundraising Platform is technical support by the Internet business-Tencent, Tencent Online Fundraising Platform use the Internet to change the traditional way of public charity, improve resource mobilization efficiency in public donation a lot in 2007, Tencent public service network launched officially, in 2008, made first appearance in Wenchuan earthquake, in 2012, the amount of donation is over 100m for the first time, in 2015, the amount of donation is up to 540 million, in 2016, became one of the first thirteen online fundraising which are certificated by government, Tencent Online Fundraising Platform is already growing to be the top in public fundraising of online fundraising platform.

The core mechanism of Tencent Online Fundraising Platform operation is connecting potential donors and public service agencies through network platform, network platform can achieve public fundraising through four functions: project presentation, donation channels structure, information feedback of donation and project, fundraising from cooperation of charitable organizations, shown in Figure 2. Mostly important, Tencent Online

\footnotetext{
${ }^{4}$ Case resource from: First-hand information is from the interview to the staff of Tencent Foundation by author; second-hand information is from Tencent public network and other media's interviews and promotional materials.
} 
Fundraising Platform fully use the advantage of Tencent, grafting platform to star social software products (QQ / Wechat) of Tencent, making donation platform reach directly to 800 million users.

Depend on the functions above, Tencent Online Fundraising Platform use various way to affect public donation influence factors system, thus prompt public donations to happen, here are the following details.

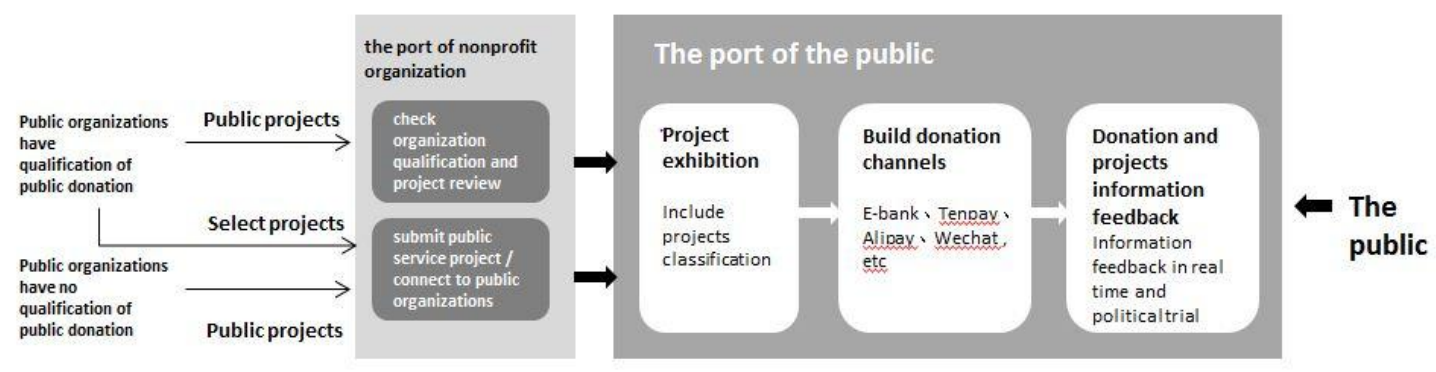

Figure 2. Function figure of "Tencent Online Fundraising Platform".

\section{Effect on the Donation Environment}

Method 1: build cooperation platform, break restrictions of the law. Charity Law states that, "Charitable organizations must get qualification of public donation when hold public fundraising activities" Therefore, public charitable projects, which only gets the qualification of public donation, can make public fundraising on Tencent Online Fundraising Platform. In order to make more excellent charitable projects can use public platform to fundraising, Tencent Online Fundraising Platform design an exchange platform to connect public-raising foundation with non-public offering foundation. The specific operating mode is: charitable organizations which are not qualified for public donation submit charitable projects of independent design, high feasibility, high social value, heart-moving to the port of nonprofit organization in Tencent Online Fundraising Platform, after that, 45 public fundraising organizations, which have built strategic partnership with Tencent, can select from these public projects in line with their own requirements. What's more, these public fundraising organizations will cooperate with the sponsors of public project and in the charge of receiving donations of the public project.

Before Tencent Online Fundraising Platform, in order to avoid legal risks, it's not uncommon that the cases of non-public offering foundations cooperating with public-raising foundation to public fundraising, for an example, Smile Angel Foundation in cooperation with Red Cross Foundation, the "Free Lunch" project launched by Deng Fei in cooperation with China Social Welfare Foundation, but most of them have an extraordinary influence. That is to say, it is difficult for many grassroots organizations have opportunities to seek cooperation with public organizations because they are lack of social relations and influence. The cooperation platform for non-public offering foundations cooperation with public-raising foundation, which is launched by Tencent, is increasing greatly the opportunities for cooperation between the two sides, providing legal opportunities of public fundraising for many grassroots organizations, and expanding the donation market in China.

Method 2: Promote peer donation, create charity culture atmosphere. The original intention of the establishment of Tencent Online Fundraising Platform is to cultivate the public awareness of public welfare,

\footnotetext{
5 Note: Figure 3 is made by author which is based on interviews and using experience of Tencent online fundraising platform.

${ }^{6}$ Note: Quote form article 22 of Charity Law of the People's Republic of China.
} 
making public welfare become a social normalcy, so that charitable donations become a habit or even a kind of life. Through the growth of nearly ten years, Tencent foundation is achieving their goals step by step.

The 800 million active users in two social software, QQ and WeChat, establish the foundation of charitable culture for Tencent foundation. Users in QQ and Wechat are mainly young people, they are the main force of development of charity in future. According to statistics, $68.45 \%$ of donation group in Tencent Online Fundraising Platform are 90s and 00s (Tencent, 2015), thus we can see the role of awaking and develop adolescent charity awareness of Tencent foundation has been highlighted.

For making further expansion on the impact of charitable culture to the public, Tencent foundation designs love transmission function of "peer donation" on the donation platform. There are two ways of, people can invite friends to donate together at any time when they choose some projects to donate on Tencent Online Fundraising Platform, on the other hand, people can share project information in Wechat friend circle for guiding friends to make donations, too. The effect of peer donation is gratifying, 2015 Tencent public data reports shows, in 2015, the amount of donation brought by "Donate together" accounted for $34.23 \%$ of all donations, the donation of a person can lead 5 to 6 people involve in donation (Tencent, 2015). The "Peer Donation" helps to make charitable donations spread among the public, thus promote the formation of strong charitable atmosphere.

\section{Effect on Non-profit Organizations / Public Welfare Projects}

Method 3: transmit charity information, enhance popularity of organization / project. Spreading the information of public welfare projects and enhancing the public's understanding of public welfare projects are the first step in public fundraising. Tencent foundation has a significant scale effect on the development of public welfare projects' popularity. Tencent foundation achieves to build the relationships between many public welfare projects and general public at the same time, develop the popularity of public welfare projects / organizations efficiently, and help Non-profit Organizations take the first step in public fundraising. And the base of 800 million active users helps to improve the efficiency of information dissemination of Tencent foundation.

Method 4: guarantee information transparency, and improve credibility of organizations / projects. Credibility is always the thorny problem in the development of Non-profit Organizations in China. The research has shown that providing organization information and opening the operational status of organizations are the most basic ways to build a bridge of trust with the public (Saxton \& Guo, 2011). The strong interaction and participation of the Internet can achieve full communications between Non-profit Organizations and the public (Lovejoy, Waters, \& Saxton, 2012; Lovejoy \& SAXTON, 2012), Tencent foundation takes full advantages of the Internet, and designs a series of information feedback mechanism to improve the transparency of Non-profit Organizations and projects.

\section{Donation Results Shown in Real-time}

From the PC to mobile, Tencent foundation updates the received donations of every project to the public on the home page in real time, including the amount of donations, the number of donors, the screen name of donors who appeal for donation together and other information.

\section{Project Progress Report}

Tencent foundation stipulates that charitable organizations must be equip with at least a staff who is responsible for information feedback work of the project special if they publish public welfare projects on the 
platform. The project officers must collect the progress information of the project on schedule (the number of people participating in donation, the amount of donations, the use of donations, etc. during this period), and do project progress reports with pictures and passages, and upload it to the platform for donors' check.

\section{Donors' Center}

On Tencent Online Fundraising Platform, users who participate in the donation can enter their own personal center to see their donation information, financial reports and progress feedback of the projects they participate in.

\section{Other Function Settings}

Besides functions above, Tencent Online Fundraising Platform also introduces two small functions for giving people the right of initiative communication. One is the "political trial". If you are a volunteer of this project, you can express your views quickly to prove the authenticity of the project through this function. The other one is "I want to feedback". The Non-profit Organizations can invite volunteers and project executives to give feedbacks about dribs and drabs through the platform in real time directly. This information can be spread out through friends' circle, and cultivate others' trust on the Non-profit Organizations and projects.

All exploration and efforts for developing the transparency of charitable projects Tencent foundation have made is extremely helpful to platform maintenance and the credibility of its organizations and projects. Public willingness to donate will be stronger and the possibility of donation will rise if the credibility increases.

\section{Effect on Fundraising Strategies}

Method 5: provide convenient channels, and reduce the cost of donations. Tencent foundation uses the advantages of the Internet and social software to provide convenient channels of information access and donations, reducing greatly the cost of public donations.

\section{Information access channel}

With the popularity of the Internet, people increasingly rely on the Internet to know relevant organization information when they are deciding to donate money to a nonprofit organization or to be a volunteer (Gordon, Knock, \& Neely, 2009). The Covenant-lite and popular characteristics of Tencent foundation can make people login the platform to view nonprofit organizations in residence and all relevant information of their projects, including organizational profiles, methods of donation, using reports of donations and so on, as long as they have a QQ or Wechat account.

Tencent foundation is also classified by the activities of public projects, which is convenient for people to find the project according to their own wishes.

\section{Donation Channels}

On Tencent Online Fundraising Platform, if you are interested in a public welfare project, then you can make one-click donation and know the progress of public projects at any time, any place. Compared to the traditional fundraising model which needs to go to the bank, or a post office for remittance and making on-site donations regularly, Tencent foundation breaks the limitation of time and space existing before, reducing the cost of searching donation channels and making donations when people participate in public welfare in the traditional way, closing the distance between the public and public charity.

Method 6: establish an incentive system, increase donations benefits. To motivate people to donate, especially persistently donate, Tencent foundation designs a rich and various incentive mechanism according to the users' characteristics and uses ports of platform like QQ and Wechat, increasing "dominant profits" of 
public donations.

\section{QQ Shanke Charity Growth System}

"QQ Shanke Charity Growth System" aims to build a QQ virtual public community for Tencent users. Users can obtain love points of growth by supporting and concerning public charity. These points will transfer into some logos-public love icons, which stand for different stages of growth of public charity, and show the first place of users' mini card icons. For young people, the lightening of public love icon is a kind of great spiritual reward, encouraging them to insist on donating to the Non-profit Organizations.

\section{Love Feedback}

Besides Charity growth system, Tencent foundation also makes full use of the company's products to provide abundant rewards for netizens participating in public charity, including issuing public badges, giving membership growth, wealth value, love package as a gift, getting online game package and etc.

\section{Peer Donations}

The two types of incentive above are commonly ways Tencent foundation used in PC time before 2014. With core products of Tencent Company changing in 2015, Tencent foundation switched to the mobile side. Incentive methods depending on QQ were no longer fit for Wechat. Therefore, Tencent foundation began to design new incentive ways-peer donations. Peer donation can make donors show their side of "loving, enthusiastic in public" in friend circle. To some extent, it can also form a kind of social pressure, and drive friends to make some generous donations, too (Bekkers \& Wiepking, 2011).

The multi-incentive mechanism builds by Tencent Online Fundraising Platform enhances public sense of experience and participation of users group, strengthen donor's perception of donation benefits, so as to urge them to donate continually.

\section{Effect On Donors}

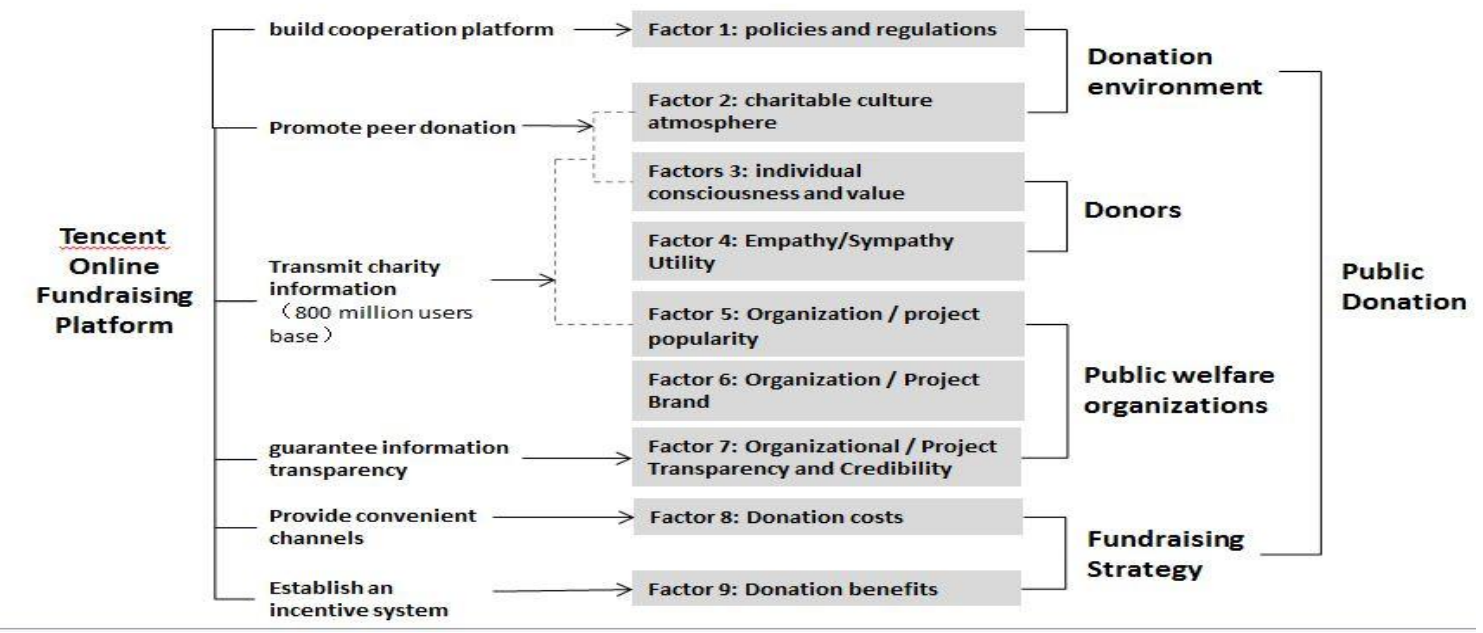

Figure 3. The specific ways of Tencent foundation improving public donation effectively.

The effects Tencent foundation has on donors are achieved by improvements of the whole social charity culture atmosphere. Tencent foundation's efforts, such as the development of the transparency of public welfare projects, the improvement of credibility of public organizations, the reduce of donation costs, will reflects in the improving of charitable value of donors. And "peer donation" has a significant effect on cultivating people's values of charitable donations. 
In conclusion, Tencent Online Fundraising Platform uses various ways to affect public donation influence factors system, so as to promote public donations. Conclusion of specific ways is shown in Figure 3.

\section{Conclusion: Improving Efficiency Mechanism of Online Fundraising Platform to}

\section{Public Donation}

Tencent Online Fundraising Platform is an excellent representative of online fundraising platform. The specific way that Tencent foundation to improve public donation is common but also has its own unique advantages. Not all network donation platforms have 800 million active users who have a directly access. Through reanalysis of the specific ways of Tencent foundation improving public donation above, we can obtain the resources that are supported by each kind of way clearly. The details is shown in Table 1. This work will not only give us greater insight into the Tencent Online Fundraising Platform but also help us sum up the network donation platform from Tencent public welfare cases to gain the public mechanism of public donation.

Table 1

Reanalysis of the Specific Ways of Tencent Foundation Improving Public Donation

\begin{tabular}{|c|c|c|}
\hline Methods & Depending & \\
\hline $\begin{array}{l}\text { Build cooperation platform, break restrictions of the } \\
\text { law }\end{array}$ & $\begin{array}{l}\text { Social network on the Internet } \\
\text { The advantage of data transmission of } \\
\text { the Internet }\end{array}$ & \multirow{6}{*}{$\begin{array}{l}\text { Advantages of Tencent } \\
\text { Company } \\
\text { Users resource } \\
\text { Production system } \\
\text { Advantages of the Internet } \\
\text { The advantage of data } \\
\text { transmission } \\
\text { Social network crossing } \\
\text { space-time } \\
\text { Pay system } \\
\text { Advantages of the United } \\
\text { Way } \\
\text { Professional } \\
\text { Scale effect }\end{array}$} \\
\hline $\begin{array}{l}\text { Promote peer donation, create charity culture } \\
\text { atmosphere }\end{array}$ & - Social network on the Internet & \\
\hline $\begin{array}{l}\text { Transmit charity information, enhance popularity of } \\
\text { organization / project ( } 800 \text { million users base) }\end{array}$ & $\begin{array}{l}\text { - The advantage of data transmission } \\
\text { of the Internet } \\
\text { Scale effect of the United Way }{ }^{7} \\
\text { Sharing resources of users of Tencent } \\
\text { Company }\end{array}$ & \\
\hline $\begin{array}{l}\text { guarantee information transparency, improve } \\
\text { credibility of organizations/projects }\end{array}$ & $\begin{array}{l}\text { The advantage of data transmission of } \\
\text { the Internet } \\
\text { Professional of the United Way }\end{array}$ & \\
\hline $\begin{array}{l}\text { Provide convenient channels, reduce the cost of } \\
\text { donations }\end{array}$ & $\begin{array}{l}\text { The advantage of data } \\
\text { transmission of the Internet } \\
\text { Pay system of the Internet }\end{array}$ & \\
\hline $\begin{array}{l}\text { Establish an incentive system, increase donations } \\
\text { benefits }\end{array}$ & $\begin{array}{l}\text { - Professional of the United Way } \\
\text { Production system of Tencent } \\
\text { Company }\end{array}$ & \\
\hline
\end{tabular}

Table 1 shows the resources that Tencent foundation depends on are mainly from three ways: Tencent Company, the Internet and advantages of the United way. Except the resource advantage of Tencent Company, both the Internet and the United way are universal.

The essence of each online fundraising platform is an online "United way" institution. Compared with other charitable institutions, the only business of "United way" is fundraising for many charitable institutions. Therefore it is professional in public fundraising and have scale effects; Compared with offline "United way" institution, it has both professional and scale effect of offline "United way" and advantages of the Internet.

So, the essence of online fundraising platform improving public fundraising efficiency is depending on the Internet, which builds an ecosystem aim for providing professional public fundraising system, friendly charity

\footnotetext{
7 the United Way refers to a way of fundraising together in market, and allocating to according to some reasonable rules. In this article, the United Way is stand for the behavior that many public organizations fundraising together.
} 
culture atmosphere, better policy environment and resource brought by cross-border cooperation.

\section{Professional Fundraising System}

The network donation platform can build a more efficient and professional fundraising system at a lower cost. The professional fundraising system should has following advantages:

First, low-cost fundraising. Compared with other solutions, the advantage of public fundraising on the platform, "low cost", can reflects in all aspects of public fundraising, including public information transmission, public information acquisition, public donations, capital use information transmission, public supervision, etc.

Second, high-efficiency fundraising. The scale effect of "United way" and high efficiency of internet social-networking and information transmission decide that online fundraising platform can transmit information and funds more quickly and widely.

Third, high transparency. Online fundraising platform should have a complete and detailed public information disclosure system that all public projects must strictly stick to. As for public organizations, it will cost less if they use unified system of online fundraising platform to publish information than building information publishing system by themselves to protect organization transparency.

Fourth, complete supervision mechanism. All online fundraising platforms can have supervision mechanism which is similar to the "political scrutiny" function of Tencent online fundraising platform, and achieve high transparency and complete supervision mechanism at lower costs by using the advantages of the Internet.

\section{Friendly Charity Culture Atmosphere}

Online fundraising platform promotes charity culture and value transmission in more various ways in virtual social network. When people return to real world from virtual social network, charity will be a habit, or even a part of life. In this respect, online fundraising platform with many users and mature social networks has a natural advantage. Relying on the four online fundraising platforms-Tencent foundation, Ant Financial, Taobao public welfare, MicroCharity, internet products, such as WeChat, Sina weibo, all have social nature and abundant users base. Therefore, they are more influential among the public, and the effect of charitable culture transmission is better.

\section{Better Policy Environment}

The Internet brings us a virtual social network world beyond real world. The emergence of this virtual space brings lots of industry regulations and policy breakthroughs, for example, the emergence of Wechat broke monopoly position of the three major telecom giants in public communication; Alipay built a new payment system based on the Internet.

And the use of fundraising platform to promote non-public institutions and public institutions in the public fund-raising in the field of GF cooperation is one of the greatest contributions to China's charity that Tencent public welfare has made. Unfortunately, not all of the network fundraising platforms have this feature. But at least, Tencent public service for other network fundraising platforms have made a very good demonstration.

\section{Resource Brought by Cross-border Cooperation}

For other network donation platform, the resources of sharing users of Tencent Company and Tencent foundation can't be copied, but cross-border cooperation which refers to cooperation between public institutions and enterprises, government, and this Internet thinking of sharing resources are very important.

The reason why Tencent foundation can stand out in many Internet donation platforms can't leave with the 
"borrowing" and "integration" resources from Tencent Company. The four major network fundraising platforms-Tencent foundation, Ant Financial, Taobao public welfare, MicroCharity, their success also depend on the backing Internet company's resources at different levels. While not all network donation platforms can have the same resources like the four major online fundraising platforms, they should also try to collaborate with companies or government agencies, "borrowing" resources from other organizations to expand the platform's influence and drive donors.

Overall, relying on the advantages of the Internet and the United Way, online fundraising platform can have a full impact on public donation influence factors system. On online fundraising platform, the public organizations can achieve the dissemination of information of public projects at very low cost but in an efficient way. At the same time, they also need to protect the transparency of the project and money according to the unified rules of platforms; donors can get public projects information and make charitable donations, they can also supervise and control public organizations easier. Besides, compared with other public fundraising solutions, online fundraising platform has an absolute advantage in charitable culture and policy environment optimization.

\section{Summary and Discussion}

How to improve public donation by online fundraising platform is the core problem of this article. This article starts with the structure of "Public Donation Influence Factors System", based on case study of "Tencent online fundraising platform", summarizing specific efficiency improving mechanism of public donation of online fundraising platform.

It is worthy to know that because the focus of this paper is the "gain" effect of online fundraising platform for public fundraising, this paper doesn't discuss about negative impact of that, the tough problems, for example, what effect the trend that the Internet companies monopoly online fundraising platform will bring to the public charity, will be carried out an analysis in other researches.

\section{References}

Aaker, J. L. (1997). Dimensions of brand personality. Journal of Marketing Research, 19(3), 347.

ATAN, R., ZAITON, S., \& WAH, Y. B. (2012). Quality information by charity organizations and its relations with donations. Recent Advances in Business Administration (p. 122).

Bekkers, R., \& Schuyt, T. (2008). And who is your neighbour? Explaining the effect of religion on charitable giving and volunteering. Review of Religious Research, 50(1), 74-96.

Bekkers, R., \& Wiepking, P. (2011). A literature review of empirical studies of philanthropy: Eight mechanisms that drive charitable giving. Nonprofit and Voluntary Sector Quarterly, 40(5),942-943.

Bruce, I. (1998). Successful charity marketing: Marketing need. Hemel Hempstead: ICSA Publishing.

CAI, Y. Q. (2011). A study on individual donation influencing factors in Mainland China. China University of Political Science and Law, 3, 21-31.

CHEN, T. X., \& YAO, M. (2012). Factors influencing individual donations to nonprofit organizations: A questionnaire survey in Guangzhou. Journal of Zhejiang University (Humanities and Social Sciences), 7, 128.

China Charity Contribution Report 2015(Lite). (2016). China Charity \& Donation Infor. China Charity Alliance, 12, 2-7.

Fong, C. M. (2007). Evidence from an experiment on charity to welfare recipients: Reciprocity, altruism, and the empathic responsiveness hypothesis. Economic Journal, 117, 1008-1024.

Gordon, T. P., Knock, C. L., \& Neely, D. G. (2009). The role of rating agencies in the market for charitable contributions: An empirical test. Journal of Accounting \& Public Policy, 28(6), 469-484.

HOU, J. D., \& DU, L. Y. (2011). Awareness and dimensional structure of influencing individual donation decision-based on empirical experience in China. Journal of Public Management, 4, 117. 
JIANG, X. M. (2011). A study on the influencing factors of individual charitable donation in China. Wuhan University of Science and Technology (pp. 24-26).

Joellen, P. (1999). Charities solicit online with pitches and fruitcakes. US News \& World Rep 78.

KANG, X. G. (1999). Power transfer-The change of China's power in transitional period. Zhejing People's Publishing House.

Karlan, D., \& List, J. A. (2006). Does price matter in charitable giving? Evidence from a large-scale natural field experiment. Social Science Electronic Publishing, 97, 1790-1791.

Lee, B. A., \& Farrell, C. R. (2003). Buddy, can you spare a dime? Homelessness, panhandling, and the public. Urban Affairs Review, 38, 299-324.

Liazos, M. G. (2000). Can States impose registration requirements on online charitable solicitor. The University of Chicago Law Review, 67(4), 1379-1407.

Lovejoy, K., \& Saxton, G. (2012). Information, community, and action: How nonprofit organizations use social media. Journal of Computer-Mediated Communication, 17, 337.

Lovejoy, K., Waters, R. D., \& Saxton, G. (2012). Engaging stakeholders through Twitter: How nonprofit organizations are getting more out of 140 characters or less. Public Relations Review, 38(2), 313-315.

National Philanthropic Trust Comments on Giving USA 2016: Annual Report on Philanthropy for 2015. (n.d.). Retrieved from http://www.4-traders.com/news/National-Philanthropic-Trust-Comments-on-ldquo-Giving-USA-2016-Annual-Report-on-Phi lanthropy-for-2--22522512/

Sargeant, A., Ford, J. B., \& West, D. C. (2006). Perceptual determinants of nonprofit giving behavior. Journal of Business of Research, 59, 157.

SAXTON, G. D., KUO, J. S., \& HO, Y. C. (2012). The determinants of voluntary financial disclosure by nonprofit organizations. Nonprofit and Voluntary Sector Quarterly, 41(6), 1051-1071.

Saxton, G., \& Guo, C. (2011). Accountability online: Understanding the web-based accountability practices of nonprofit organizations. Nonprofit and Voluntary Sector Quarterly, 40(2), 270-295.

SHI, F. G. (2016). The problems and the construction of the supervision system of the network collection platform. Economic and Social Science Research, 9, 471.

Simmel, G. (1955). Conflict and the Web of Group-Affiliation (pp. 140-142). New York: Free Press.

Smith, J. R., \& McSweeney, A. (2007). Charitable giving: The effectiveness of a revised theory of planned behaviour model in predicting donating intentions and behaviour. Journal of Community \& Applied Social Psychology, 17, 298.

Sohu. (n.d.). China's first Charity Law will be put into implementation January 1, 13 platform will enter into online fundraising. Retrieved from http://mt.sohu.com/20160902/n467342445.shtml

Tankersley, D., Stowe, C. J., \& Huettel, S. A. (2007). Altruism is associated with an increased neural response to agency. Nature Neuroscience, 10, 150-151.

Tencent. (2015). Tencent public charity data report. Retrieved from http://gongyi.qq.com/a/20160318/053250.htm

Todd, S. J., \& Lawson, R. W. (1999). Towards a better understanding of the financial donor: An examination of donor behaviour in terms of value structure and demographics. International Journal of Nonprofit and Voluntary Sector Marketing, 4, 235-244.

Van Lange, P., Bekkers, R., Schuyt, T., \& Van Vugt, M. (2007). From games to giving: Social value orientation predicts donations to noble causes. Basic and Applied Social Psychology, 29, 375-384.

Vestlund, L. (2006). “Why do people give?”. In The Nonprofit Sector (p. 568). New Haven, CT: Yale Press.

WANG, G. H., \& ZHANG, X. G. (2014). A comparative study on the mode of online charity operation. China Social Science Research, 3, 104-110

WANG, M., \& JIA, X. J. (2003). Issues on China's NGO Legal Policy. Journal of Tsinghua University (Philosophy and Social Sciences), 6, 100.

Wong, H. Y., \& Merrilees, B. (2005). A brand orientation typology for SMEs: A case research approach. Journal of Product and Brand Management, 14(3), 156-160.

XU, W. W. (2013). Public Fundraising by organizational channels-The Enlightenment of American NGO Public Fundraising to China. Lanzhou Academic Journal, 6, 122

ZHANG, D, S., \& FU, X. J. (2014). MicroCharity transmission on Weibo platform. Media Observer, 3, $26-28$.

ZHANG, G. F., \& HOU, J. W. (2014). An analysis of development and future of microcharity. China Youth Study, 10 , 41-47.

ZHANG, Y. X. (2013). A study on promotion strategy of nonprofit organizations' credibility. Journal of Financial and Economic Problems Research, 5, 172. 